I Universidade Federal do Rio de Janeiro (UFRJ), Programa de Pós-Graduação

em Sociologia e Antropologia, Rio de Janeiro, RJ, Brasil

cavalcanti.laura@gmail.com

https://orcid.org/0000-0002-5415-309I

Maria Laura Viveiros de Castro Cavalcanti'

\title{
VOZES DE CAMPOS DO JORDÃO, DE ORACY NOGUEIRA, EM TEMPOS DE PANDEMIA
}

Sabemos pouco sobre o coronavírus, causador da atual pandemia que espalha dor e tristeza no mundo. Mas entendemos claramente seu imenso escopo de contágio que indica o isolamento social como a única prevenção possível no momento, de modo a ampliar as condições de mitigação dos efeitos danosos da doença por parte da saúde pública. Sabemos também que o vírus ataca especialmente os pulmões e leio, em boletim divulgado em 24 de março de 2020 pela Organização Mundial de Saúde (OMS), o quanto são particularmente vulneráveis aqueles que têm os pulmões enfraquecidos pela tuberculose.

Em nível epidêmico, a tuberculose foi controlada no Brasil, embora o número de casos tenha crescido nas últimas décadas. Na minha experiência próxima, nos últimos anos, quatro alunos e uma jovem amiga adoeceram, precisando submeter-se ao intenso tratamento de seis meses com a combinação de quatro antibióticos, descobertos nos anos I950 e I960. Mais de um milhão de pessoas ainda morrem da doença no mundo, diz o mesmo boletim da OMS. Meu pai, no início dos anos I960, contraiu tuberculose, e nos vimos, eu e minha irmã mais nova, encaminhadas para a casa de nossos tios durante as semanas iniciais de seu tratamento. Pouco se falava sobre isso; o desejo de suprimir uma doença que a todos assustava escondia o assunto nas zonas turvas do silenciamento daquilo que tanto incomodava. Mas as ciências sociais apostam no valor do conhecimento e insistem teimosamente na busca de como formular os problemas que nos inquietam em termos que nos ajudem a compreendê-los, dimensioná-los e quiçá sobre eles atuar de modo construtivo. 
Em I936, o sociólogo Oracy Nogueira (I917-I996), natural de Cunha, SP, então com I 9 anos de idade, foi diagnosticado com tuberculose e afastou-se do convívio familiar para tratamento em São José dos Campos. Quando retornou, já na capital paulista, começou a formação para tornar-se professor primário seguindo a carreira de seus pais; até que, em I939, um Anuário da Escola Livre de Sociologia e Política caiu-lhe às mãos e levou-o no ano seguinte ao bacharelado em ciências sociais naquela instituição; e logo ao mestrado, para o qual elegeu como tema de pesquisa a tuberculose como experiência social em outro centro de internamento na cidade de Campos do Jordão. Em I945, ele concluía, sob orientação de Donald Pierson (I945a, I945b), o precursor trabalho Vozes de Campos do Jordão: experiências sociais e psíquicas do tuberculoso pulmonar no Estado de São Paulo (Nogueira, 2009). ${ }^{\text {I }}$

O contágio fácil da covid-I9, o perigo do contato físico, a ameaça que o convívio com crianças pequenas, por sorte assintomáticas ou imunes (?), passou a significar para os mais velhos (avó de cinco netos, e um por chegar em breve, sinto diariamente a estranheza do afastamento), o isolamento social, em suma, são elementos que ressoam na experiência social da tuberculose pulmonar, sobre a qual Oracy Nogueira lançou nos anos I940 o olhar inovador das ciências sociais que também aqui se iniciavam (ver Cavalcanti, I996).

Nosso autor buscou compreender como os indivíduos se tornavam socialmente "doentes" e examinou todo o processo do "tornar-se doente", do diagnóstico à almejada cura, passando pelo internamento com a separação do doente de seu círculo próximo, ou seja, pela segregação que, nos anos I940, acompanhava o tratamento geralmente prolongado da tuberculose. O livro transpira o conceito de estigma com que mais tarde Erving Goffman (I988) batizaria a forma de demarcar a distância social, também expressa no comportamento social relativo aos tuberculosos.

Para além da causa orgânica responsável pelo desenvolvimento da doença e das práticas terapêuticas adotadas para combatê-la, interessavam a Nogueira as representações, os significados e estereótipos atribuídos à doença que informavam as condutas sociais. Atitudes e ideias integravam, na visão do autor, um complexo cultural que se impunha tanto aos sãos quanto aos doentes. O ponto de vista dos doentes, no entanto, foi seu principal foco por meio do convívio com um grupo de I04 pessoas "portadores de tuberculose pulmonar", isoladas para tratamento em uma estação de cura em Campos do Jordão, a sua Montanha Mágica.

$\mathrm{Na}$ estação de cura, os doentes tornavam-se um grupo social cuja interação regulava a conduta de seus membros com verdadeiros ritos de passagem e gíria própria, por meio dos quais os novos integrantes se socializavam naquele novo ambiente, feito de ideias, atitudes e valores característicos. Esses doentes, por sua vez, encontravam-se imersos em um complexo processo de negociação da realidade por meio da interação cotidiana com enfermeiros, médicos, inter- 
nos e sãos, e com a própria população local que se afastava dos circuitos urbanos por onde a circulação dos internos era permitida. A pesquisa associou aos métodos quantitativos - quadros estatísticos e preocupação com a objetividade do conhecimento produzido - métodos qualitativos - observação participante, entrevistas de histórias de vida, questionários e exame de documentos íntimos, como os diários e correspondências de alguns doentes cedidos ao autor. O livro teve expressiva recepção quando de sua edição em I950, e parte das análises recebidas, encontradas no Fundo Oracy Nogueira, foi incorporada à edição de 2009 do livro que organizei para a Editora Fiocruz. Luiz de Castro Faria, que foi meu professor em cursos de pós-graduação no PPGAS do Museu Nacional/UFRJ, referia-se ao livro como "um clássico esquecido". Não mais.

Nogueira inovou ao propor ao olhar sociológico perguntas até então inusitadas: como os indivíduos recebem o diagnóstico da doença? Como seus familiares o fazem? Como a passagem da condição de são à de doente afeta a subjetividade da pessoa envolvida? Como a discriminação e os estereótipos relacionados à doença são introjetados pelos próprios doentes? Como um recém-chegado se socializa na estação de cura? Como médicos, enfermeiros, doentes e sãos se confrontam na experiência do dia a dia? O "ambiente tuberculoso" revelou-se então com seus grupos, suas regras, seus valores e representações próprios, com seus conflitos e suas formas de controle social, e com seu repertório próprio de modos de pensar, sentir e agir. O livro nos aproxima dessa experiência, desfaz preconceitos, redimensiona a doença como experiência vivida, qualificando como também decisivas para sua compreensão as dimensões socioculturais.

A tuberculose ainda preocupa, embora a conduta terapêutica da segregação e sua dimensão epidêmica tenham sido superadas. Campos do Jordão é hoje uma cidade de turismo ecológico. Mas a criatividade, acuidade e empatia com que Nogueira registrou suas vozes permanecem convidando novas gerações de leitores a ouvi-las. E elas parecem soar mais alto em nossos tempos de covid-I 9 .

Recebido em 2I/IO/2020 | Aprovado em 06/05/202I

Maria Laura Viveiros de Castro Cavalcanti é professora titular da Universidade Federal do Rio de Janeiro atuante no Programa de PósGraduação em Sociologia e Antropologia do Instituto de Filosofia e Ciências Sociais. Pesquisadora do CNPq. Suas principais áreas de pesquisa são teoria antropológica, ritual e análise simbólica, narrativas e escrita etnográfica, história da antropologia, estudos de folclore e cultura e rituais populares. Seus livros mais recentes são Drama, ritual e performance: a antropologia da Victor Turner e a co-organização da coletânea Carnaval sem fronteiras: as escolas de samba e suas artes mundo afora. 


\section{NOTA}

I Nogueira se notabilizou também por suas formulações comparativas acerca do racismo no Brasil e nos Estados Unidos. Para saber mais sobre o autor, ver Cavalcanti, 2020. O Fundo Oracy Nogueira encontra-se hoje sob a guarda da Casa de Oswaldo Cruz/Fiocruz (www.arch.coc. fiocruz.br). Em www.marialauracavantanti.com.br podem ser encontrados também, além do inventário completo do Fundo, diversos textos do autor e sobre o autor.

\section{REFERÊNCIAS}

Cavalcanti, Maria Laura Viveiros de Castro. (2020). Preconceito racial e estigma da doença na obra pioneira de Oracy Nogueira. BEROSE - International Encyclopaedia of the Histories of Anthropology. Paris. URL BEROSE: article2I 22. html.

Cavalcanti, Maria Laura Viveiros de Castro. (I996). Oracy Nogueira e a antropologia no Brasil: o estudo do estigma e do preconceito racial. Revista Brasileira de Ciências Sociais, 3I/II, p. 5-28.

Goffman, Erving. (I988). Estigma: notas sobre a manipulação da identidade deteriorada. Rio de Janeiro: LTC.

Nogueira, Oracy. (2009). Vozes de Campos do Jordão: experiências sociais e psíquicas do tuberculoso pulmonar no Estado de São Paulo. Organização, apresentação e notas de Maria Laura Cavalcanti. Rio de Janeiro: Ed. Fiocruz.

Pierson, Donald. (1945a). Estudos de ecologia humana. São Paulo: Livraria Martins Editora.

Pierson, Donald (I945b). Estudos de organização social. São Paulo: Livraria Martins Editora. 
Palavras-chave

Doença como experiência social; tuberculose;

Oracy Nogueira; segregação;

Escola Livre de Sociologia e Política.

Keywords

Illness as a social experience; tuberculosis; Oracy Nogueira; segregation; Free School of Sociology and Politics.
VOZES DE CAMPOS DO JORDÃO, DE ORACY NOGUEIRA, EM TEMPOS DE PANDEMIA

\section{Resumo}

Escrito no início do primeiro ano da pandemia, em abril de 2020, o artigo relembra a pesquisa precursora de Oracy Nogueira que fez da doença um tema sociológico. Vozes de Campos do Jordão: experiências sociais e psíquicas do tuberculoso pulmonar no Estado de São Paulo, re-editado pela Fiocruz em 2009, resulta de dissertação de mestrado defendida em I 945 na Escola Livre de Sociologia e Política de São Paulo. Nogueira busca, para além das causas orgânicas, as representações, os significados e estereótipos atribuídos à doença que informavam a conduta social segregadora. Do diagnóstico à almejada cura, passando pelo isolamento dos doentes em estação de cura, o estudo desvenda a experiência da doença sob os pontos de vista sociológico e psicológico. O conceito de estigma, mais tarde cunhado por Erving Goffman para dar conta desse tipo de construção da distância social transpira no estudo de Nogueira.

\section{ORACY NOGUEIRA'S VOICES FROM CAMPOS DO JORDÃO,} IN COVID-19 PANDEMIC TIMES

\section{Abstract}

Written at the beginning of the covid-I9 pandemics, in April 2020, the article recalls the innovative research by Oracy Nogueira that developed a sociological approach to the subject of illness. Voices from Campos do Jordão: social and psychic experiences of pulmonary tuberculosis in the State of São Paulo, re-edited by Fiocruz in 2009, results from his master's thesis, defended in 1945 at the Free School of Sociology and Politics of São Paulo. Beyond the organic causes, Nogueira seeks the representations, meanings and stereotypes attributed to the disease that informed a segregating social conduct. From diagnosis to the desired cure, through the experience of isolation in a healing clinic, the study unveils the sociological and psychological dimensios of the disease. The concept of stigma, later coined by Erving Goffman to account for this type of social distance, insinuates itself in the approach proposed by Nogueira. 